\title{
Commentary: Aortic root enlargement, a useful and reproducible way to a larger prosthesis
}

\author{
Manuel J. Antunes, MD, PhD, DSc
}

From the Center of Cardiothoracic Surgery, University Hospital and Faculty of Medicine, Coimbra, Portugal. Disclosures: Author has nothing to disclose with regard to commercial support.

Received for publication Sept 14, 2019; revisions received Sept 14, 2019; accepted for publication Sept 16, 2019; available ahead of print Sept 24, 2019.

Address for reprints: Manuel J. Antunes, MD, PhD, DSc, Clinic of Cardiothoracic Surgery, University of Coimbra Medical School, 3000-075 Coimbra, Portugal (E-mail: mjantunes48@ sapo.pt).

J Thorac Cardiovasc Surg 2020;160:924-5

$0022-5223 / \$ 36.00$

Copyright (c) 2019 by The American Association for Thoracic Surgery

https://doi.org/10.1016/j.jtcvs.2019.09.049

In the current era of percutaneous aortic valve implantation (TAVI, which I prefer to transcatheter aortic valve replacement [TAVR], emphasizing implantation vs replacement), surgical aortic valve replacement (AVR) must have its methods improved if it is to compete and survive. This applies particularly to treating patients with small aortic roots. In these circumstances, aortic root enlargement (ARE), which can be performed with several previously described techniques, to permit implantation of larger prostheses and thus avoid the problem of patient-prosthesis mismatch has gained increasing acceptance by the surgical community. In the case of bioprostheses, larger sizes may also facilitate the later use of valve-in-valve TAVI. A possible disadvantage of ARE is increased technical difficulty with longer operation times, which may condition a higher incidence of complications. Several publications, however, have already attested to the safety and reproducibility of the procedure. ${ }^{1,2}$

In their article published in this issue of the Journal, Tam and colleagues $^{3}$ from Canada compare AVR with ARE versus AVR alone for early and late mortality and secondary safety outcomes in a series of 16,656 patients undergoing AVR in 11 Ontario institutions. ${ }^{3}$ Nearly half of the population was operated in 1 of the centers, and the early results of this subgroup were earlier reported by the Toronto General Hospital group. ${ }^{4}$ The study population is very heterogeneous; after propensity-score matching of 809 pairs for AVR versus AVR with ARE, however, there were no differences in 30-day mortality or in rates of chest reopening for bleeding, permanent pacemaker implantation, and blood transfusions. Late mortalities in the course of 8 years were also similar between groups. Adding coronary artery bypass grafting also did not make a difference, except for the incidence of perioperative bleeding. Tam and colleagues $^{3}$ therefore conclude that "the addition of ARE to isolated AVR can be safely performed to increase implanted prosthesis size without compromising early or late mortality."

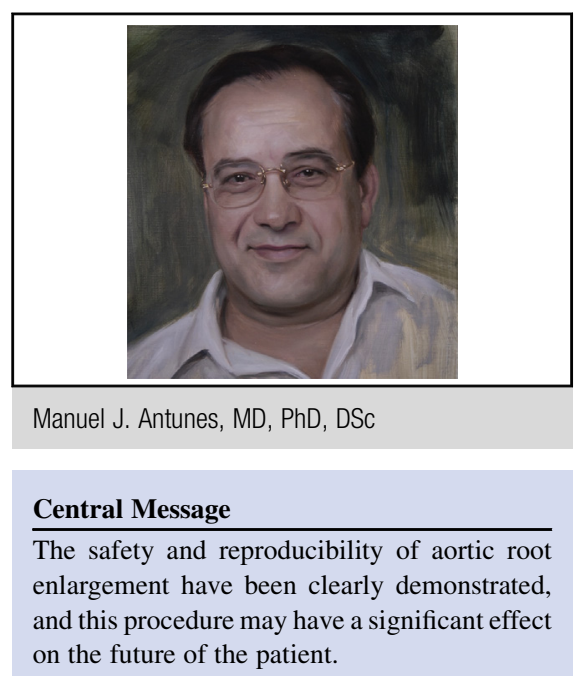

See Article page 908.

This study was well conducted, and there is little to comment on regarding the methodology used. The work was facilitated by the use of the several regional and national registries and databases, which are of uncontested quality and completeness of data and permit a complete follow-up of the population from birth to death. On the other hand, it was based on a complex statistical analysis, which was further improved during the reviewing process. Overall, $8.8 \%$ of patients submitted to AVR underwent concomitant ARE. This is a good percentage, if still significantly lower than the $23 \%$ in the experience of the Toronto group, but this has to be matched to the type and morphology of the population, which varies from region to region. The conclusions derived by Tam and colleagues ${ }^{3}$ are well justified but do not add significantly to our knowledge of this subject, because similar conclusions have been reached by other studies, as indicated above. It is a fact that these "mostly were observational studies that have not adjusted for baseline differences in the patient populations" and usually only reported early outcomes. The fact that the current work includes patients from a large number of institutions in Canada, however, further attests to the reproducibility of the method.

There are some limitations of the current study, as also acknowledged by Tam and colleagues. ${ }^{3}$ One relates to the absence of information regarding annular size and surgical expertise. In this regard, we do not know about differences between the surgical centers and individual surgeons 
involved, because this information is not included in the different databases used. As with any other procedure, outcomes depend on the volume of ARE procedures performed, with a learning curve applying. Nonetheless, Tam and colleagues ${ }^{3}$ found that academic and high-volume AVR centers were more likely to perform ARE and that the rate of ARE procedures performed steadily increased through the years. In my experience, even lessexperienced surgeons can do it with similar results, although this may not be true with some variations of the technique.

We use a simpler modification of the earlier Nicks technique, ${ }^{5}$ which we described in $1983,{ }^{6}$ that extends the widening down to the mitroaortic curtain but does not involve the anterior mitral valve leaflet, which is in contrast with the Manouguian technique ${ }^{7}$ and includes an upwards tilting of the prosthesis. Unfortunately, again, Tam and colleagues ${ }^{3}$ did not provide details about the surgical techniques used in the different institutions and by individual surgeons, nor is there any information about the type and size of prostheses used, with the implantation of biologic prostheses being more facilitated by enlargement procedures.

In conclusion, despite of these shortcomings, I believe that this article will help to promote ARE, a policy that we have pursued for several decades, with increased frequency and good results. ${ }^{1,8}$ The safety and reproducibility of the method have been clearly demonstrated, and the procedure may have a significant effect on the future of the patient.

\section{References}

1. Correia PM, Coutinho GF, Branco C, Antunes MJ. Long-term follow-up of patients undergoing aortic root enlargement for insertion of a larger prosthesis. Eur J Cardiothorac Surg. 2016;50:82-8.

2. Haunschild J, Scharnowski S, Mende M, von Aspern K, Misfeld M, Mohr FW, et al. Aortic root enlargement to mitigate patient-prosthesis mismatch: do early adverse events justify reluctance? Eur J Cardiothorac Surg. 2019;56:335-42.

3. Tam DY, Dharma C, Rocha RV, Ouzounian M, Wijeysundera HC, Austin PC, et al Early and late outcomes following aortic root enlargement: a multicenter propensity matched cohort analysis. J Thorac Cardiovasc Surg. 2020;160: 908-19.e15.

4. Rocha RV, Manlhiot C, Feindel CM, Yau TM, Mueller B, David TE, et al. Surgical enlargement of the aortic root does not increase the operative risk of aortic valve replacement. Circulation. 2018;137:1585-94.

5. Nicks R, Cartmill T, Bernstein L. Hypoplasia of the aortic root. The problem of aortic valve replacement. Thorax. 1970;25:339-46.

6. Kinsley RH, Antunes MJ, McKibbin JK. Enlargement of the narrow aortic roo and oblique insertion of a St Jude prosthesis. Br Heart J. 1983;50:330-2.

7. Manouguian S, Seybold-Epting W. Patch enlargement of the aortic valve ring by extending the aortic incision into the anterior mitral leaflet. New operative technique. J Thorac Cardiovasc Surg. 1979;78:402-12.

8. Coutinho GF, Correia PM, Paupério G, de Oliveira F, Antunes MJ. Aortic roo enlargement does not increase the surgical risk and short-term patient outcome? Eur J Cardiothorac. 2011;40:441-7. 